\title{
HAUSARZTPATIENTEN ÜBER 65
}

\section{Schwindel kommt oft vom Herzen}

Schwindel bei älteren Patienten hat häufig mehr als eine Ursache. In den meisten Fällen (57\%) besteht ein Zusammenhang mit Herz-Kreislauf-Krankheiten, wie eine Studie bei hausärztlich betreuten Patienten im Alter von 65 bis 95 Jahren ergeben hat. Bei $25 \%$ der Patienten war der Schwindel durch Medikamente mitverur- sacht: Jeder Dritte erhielt drei oder mehr Medikamente, die das Sturzrisiko erhöhen. Vestibuläre Störungen, die bei jüngeren Schwindelpatienten beim Facharzt im Vordergrund stehen, wurden nur bei $14 \%$ der Patienten als Ursache ausgemacht, psychische Erkrankungen bei $10 \%$. Ann Fam Med 2010;8:196-205

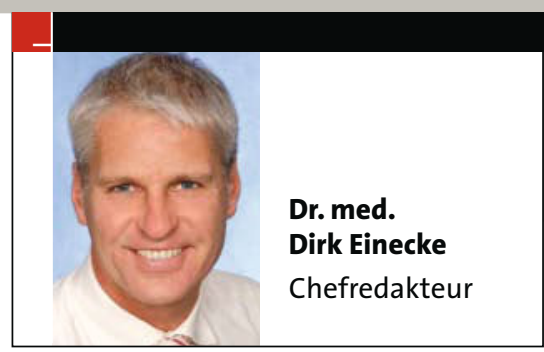

TYP-2-DIABETES

\section{Zahnfleischbluten behandeln, dann bessert sich der Blutzucker}

Schon länger wird ein Zusammenhang zwischen Parodontose und Diabetes vermutet. Die Prozesse, die durch die Zahnfleischentzündung ausgelöst werden, sollen an der Entstehung der Insulinresistenz beteiligt sein. Eine Cochrane Metaanalyse hat nun bestätigt, dass eine $\mathrm{Pa}$ rodontosebehandlung ein sinnvoller Bestandteil der Therapie des Typ-2-Diabetes sein könnte. Insgesamt wurden 690 Studien analysiert. Dabei zeigte sich, dass die erfolgreiche Behandlung einer Parodontose bei Typ-2-Diabetikern mit einem niedrigeren Blutzuckerspiegel einhergeht. Für Typ-1-Diabetiker lagen nicht genug aussagekräftige Daten vor.

Pressemitteilung der Peninsula College of Medicine and Dentistry

\section{SCHWIERIGE ENTSCHEIDUNG Zweifel einfach wegwaschen}

Es gibt Situationen im Leben, in denen man sich nur schwer entscheiden kann. Danach bleiben oft quälende Zweifel zurück. Um damit besser umgehen zu können, wird normalerweise die gewählte Variante auf- und die abgelehnte Variante abgewertet. Nun haben zwei Studien an 40 bzw. 85 Freiwilligen gezeigt, dass sich Unsicherheiten nach einer knappen Entscheidung ganz einfach zerstreuen lassen: Probanden, die nach der Beschlussfassung ihre Hände wuschen, hatten sich den Studienautoren zufolge nicht nur von Schmutz, sondern auch von ihren Zweifeln reingewaschen.

Science 2010;328:709

\section{LEBENSERWARTUNG BEI PAAREN}

\section{Gleichaltrige Männer sind gut für die Frauen}

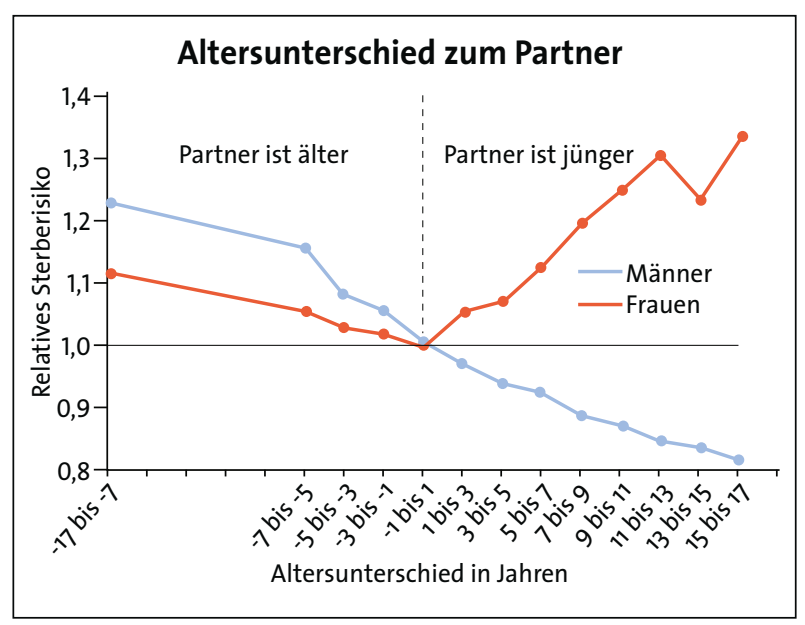

Frauen sollten möglichst einen gleichaltrigen Mann heiraten. Ihre Aussichten für ein langes Leben sind dann nämlich am besten. Anders bei Männern: Sie leben umso länger, je jünger ihre Partnerin ist. Dass ein jüngerer Partner für Frauen eher lebensverkürzend ist, hat eine Studie des Max-Planck-Instituts für demografische Forschung in Rostock festgestellt: Frauen, die einen sieben bis neun Jahre jüngeren Mann heiraten, haben ein um 20\% höheres Mortalitätsrisiko. Die Autoren vermuten, dass Paare, bei denen der Mann jünger ist, damit gegen soziale Normen verstoßen. Dies wiederum könne soziale Sanktionen nach sich ziehen, die gesundheitsschädigenden Stress erzeugen. Unabhängig davon bleibt die Tatsache bestehen, dass verheiratete Männer und Frauen im Schnitt länger leben als unverheiratete.

Demography 2010;47(2):313

Frauen profitieren gesundheitlich nicht von einem jüngeren Partner. 